\title{
КОНЦЕПЦИЯ СПРАВЕДЛИВОЙ СТОИМОСТИ В ОБЩЕЙ КОНЦЕПЦИИ БУХГАЛТЕРСКОГО УЧЕТА
}

\author{
(C) 2021 Савин А. A. \\ кандидат экономических наук, профессор Департамента аудита и корпоративной отчетности \\ Финансовый университет при Правительстве Российской Федерации, Россия, Москва \\ E-mail: aasavin@fa.ru
}

Один из основополагающих принципов составления финансовой отчетности - отражение достоверной информации о финансовом положении организации. Исходя из этого, тот же принцип должен применяется всем экономическими субъектами при ведении бухгалтерского учета, так как бухгалтерские регистры являются основным источником информации при составлении финансовой отчетности, вне зависимости от применяемых стандартов при ее составлении.

Ключевые слова: учет, анализ, аудит, налогообложение, право, взаимосвязь

В отечественной законодательной системе отсутствуют нормативно-правовые акты, законодательно регулирующие отражение активов и обязательств в финансовой отчетности по справедливой стоимости. Однако согласно п. 7.1. ПБУ 1/2008 «Учетная политика организации», в случае если по какому-либо вопросу ведения бухгалтерского учета в федеральных стандартах бухгалтерского учета не установлены способы и методы для ведения бухгалтерского учета, то каждый экономический субъект должен разработать собственный способ ведения бухгалтерского учета, исходя из требований, установленных законодательством Российской Федерации о бухгалтерском учете, федеральными и (или) отраслевыми стандартами [1].

Для выполнения вышеуказанного требования могут использовать нижеперечисленные документы в соответствующей последовательности:

a) международные стандарты финансовой отчетности;

б) положения федеральных и (или) отраслевых стандартов бухгалтерского учета по аналогичным и (или) связанным вопросам;

в) рекомендации в области бухгалтерского учета» [1].

То есть при разработке учетной политики и последующем ее применении экономические субъекты должны применять, в первую очередь, нормы международных стандартов финансовой отчетности.

В системе МСФО существует отдельный стандарт, вводящий понятие «Справедливая стоимость» и обозначивающий сферу применения данного стандарта.
Справедливая стоимость - это цена, которая была бы получена при продаже актива или уплачена при передаче обязательства в ходе обычной сделки между участниками рынка на дату оценки [2, п. 9].

Согласно п. 11 MCФO (IFRS) 13 «Оценка справедливой стоимости» оценка справедливой стоимости должна проводиться в отношении конкретного вида актива или обязательства (или группы донородных активов/обязательств) [2].

Следовательно, при оценке для отражения наилучшей справедливой оценки должны учитываться все существенные характеристики актива или обязательства, так как если бы производился расчет цены такого актива ли обязательства на рыночных условиях. К примеру, должны быть учтены как минимум следующие характеристики:

- текущее состояние актива (для объекта основных средств - степень износа, степень устаревания),

- местонахождение актива (в некоторых случаях затраты на вывоз объекта с местонахождения выше стоимости самого объекта),

- наличие обременений на использование и продажу (например, арендованные основные средства имеют ограничения на использование/ перемещение и передачу, закрепленные в самом договоре аренды).

Влияние каждой из вышеперечисленных или других характеристик должно оцениваться и будет меняться в зависимости от того, каким образом данная характеристика учитывалась бы участниками рынка.

Так, к примеру, для целей подготовки консолидированной финансовой отчетности спра- 
ведливая стоимость дебиторской задолженности рассчитывается путем дисконтирования будущих потоков денежных средств (для учета временной стоимости денег) с использованием текущей рыночной процентной ставки, применяемой к аналогичным финансовым инструментам (например, депозитам) на отчетную дату.

Согласно п. 13 МСФО (IFRS) 13 «Оценка справедливой стоимости»: актив или обязательство, оцениваемые по справедливой стоимости, могут представлять собой:

1. или отделимый актив или обязательство (напр., финансовый инструмент или нефинансовый актив);

2. или группу активов, обязательств, которые могут учитываться как единица, генерирующая денежные потоки (ЕГДС) или как отдельный бизнес [2, п.13].

Пояснения к данному стандарту (п. В2) говорят: что целью оценки справедливой стоимости является определение адекватной цены, по которой могла бы быть осуществлена рыночная сделка по продаже конкретного актива или обязательства на дату проводимой оценки.

Так, для осуществления оценки справедливой стоимости требуется определение всех нижеуказанных аспектов:

- идентификация актива или обязательства, подлежащего оценке сообразно его единице учета);

- определение основного (или наиболее выгодный) рынка для осуществления сделки в отношении данного актива или обязательства;

- способ оценки, релевантный для расчета справедливой стоимости с учетом всей информации для получения исходных данных: экономические допущения, которые использовались бы участниками рынка при определении цены на актив или обязательств [2, п. В2].

В доказательство вышесказанного, автором рассматривается применение концепции справедливой стоимости на примере дебиторской задолженности при представлении информации в отчетности, составленной в соответствии МСФО и РСБУ.

Согласно МСФО (IFRS) 13 «Оценка справедливой стоимости», дебиторская задолженность относится к финансовым активам, оцениваемым по справедливой стоимости. Методология оценки относится к сфере применения МСФО 9 «Финансовые инструменты» [3].

Дебиторская задолженность отражается в финансовой отчетности за вычетом резервов под ожидаемые кредитные убытки, так формируется наиболее достоверная оценка данной категории активов.

Данный стандарт МСФО 9 «Финансовые инструменты» демонстрирует одну из лучших моделей оценки справедливой стоимости активов, т.к. в отличие от предыдущего стандарта МСФО (IAS) 39, в котором применялась модель понесенных убытков, данный стандарт предлагает модель ожидаемых кредитных убытков, то есть учитывает будущие, прогнозные данные о получаемых денежных потоках и вероятности и доле убытков [4].

Оценочный резерв под ожидаемые кредитные убытки по дебиторской задолженности рассчитывается и создается на основании собственной оценки Компании ожидаемых кредитных убытков в течение всего срока жизни договоров (срока действия дебиторской задолженности).

Кредитные убытки представляют собой разницу между суммой договорных денежных потоков, причитающихся организации в соответствии с договором, и всеми денежными потоками, которые ожидается получить (т.е. все суммы потенциального недополучения денежных средств), дисконтированные по эффективной процентной ставке, изначально заложенной в договоре. Однако и здесь имеет место индивидуальный подход к оценке - это возможно при наличии информации об ухудшении кредитоспособности контрагента, отказа от выполнения договорных обязательств, повлекшие за собой убытки компании.

Перечень факторов необходимых для достоверной оценки активов (в частности дебиторской задолженности) в целях применения концепции справедливой стоимости при формировании показателей финансовой отчетности приведен на рис. 1.

Ожидаемые кредитные убытки представляют собой расчетную оценку, взвешенную с учетом вероятности, кредитных убытков. Кредитные убытки оцениваются как приведенная стоимость всех ожидаемых недополучений денежных средств (т.е. разница между денежными потоками, причитающимися компании в соответствии с договором, и денежными потоками, которые компания ожидает получить).

Для учета временной стоимости денег величина ожидаемых кредитных убытков дисконтируется с использованием эффективной процент- 


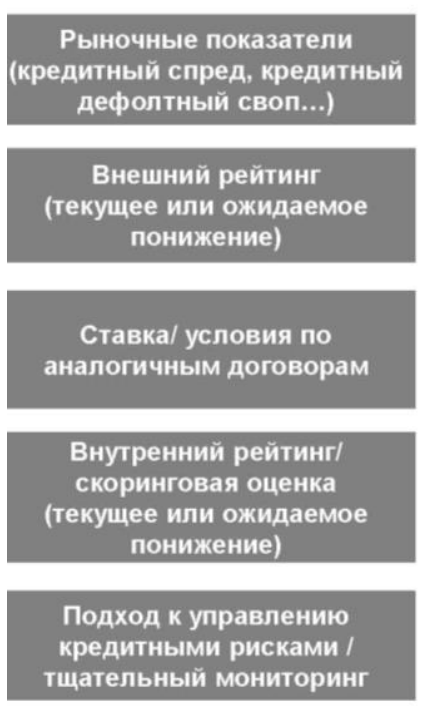

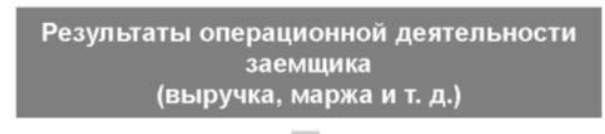

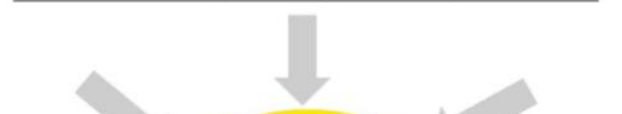

Оценка

существенного увеличения кредитного риска

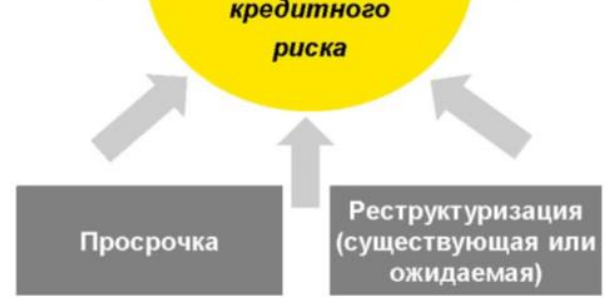

Коммерческие, финансовые или экономические условия (процентная ставка, безработица..)

Правовые, экономические или технологические условия

Обеспечение, гарантия или финансовая поддержка, если они влияют на вероятность дефолта

Статус платежей и поведение

Распространение кризисных явлений

\section{Puc. 1 Перечень факторов необходимых для достоверной оценки активов}

ной ставки по соответствующему финансовому активу.

Таким образом, в примечаниях к финансовой отчетности представление информации о дебиторской задолженности может иметь вид, показанный в таблице ниже.

То есть информация о дебиторской задолженности представляется в разрезе сроков просрочки, с расчетом резерва по каждой стадии, что несомненно повышает достоверность показателей отчетности.

В РФ отсутствует нормативно правовой акт, который бы способствовал применению концепции справедливой стоимости в бухгалтерском учете. Ожидается, что с внедрением полного комплекта Федеральных стандартов бухгалтерского учета (ФСБУ), разрабатываемых Министерством финансов РФ на основе МСФО, достоверность предоставляемой в финансовой отчетности повысится, т.к. основные подходы МСФО найдут отражение в отечественных стандартах [5].

На практике в настоящее время в российском учете скорее реализуется концепция сближения бухгалтерского и налогового учета, нежели концепция сближения российских и международных стандартов.

Так, возвращаясь к примеру с дебиторской задолженностью, компании часто создают резервы, основываясь на требованиях статьи 266 Налогового кодекса РФ [6, ст. 266].

Сумма резерва по сомнительным долгам определяется по результатам проведенной инвентаризации дебиторской задолженности на конец отчетного периода. Расчет производится следующим образом:

1) Срок возникновения дебиторской задолженности свыше 90 дней - сумма резерва равна

\begin{tabular}{|l|c|c|c|c|}
\hline & $\begin{array}{l}\text { Дебиторская за- } \\
\text { долженность до } \\
\text { вычета резерва } \\
\text { под обесцене- } \\
\text { ние }\end{array}$ & $\begin{array}{l}\text { Резерв под обес- } \\
\text { ценение }\end{array}$ & $\begin{array}{l}\text { Дебиторская } \\
\text { задолженность } \\
\text { за вычетом } \\
\text { резерва под } \\
\text { обесценение }\end{array}$ & $\begin{array}{l}\text { Отношение } \\
\text { резерва к сумме } \\
\text { дебиторской за- } \\
\text { долженности до } \\
\text { вычета резерва }\end{array}$ \\
\hline Дебиторская задолженность & 563839 & $(8535)$ & 555304 & $1,5 \%$ \\
\hline $\begin{array}{l}\text { Дебиторская задолженность, } \\
\text { просроченная на срок менее } \\
\text { 30 дней }\end{array}$ & 205623 & $(3257)$ & 202366 & $1,6 \%$ \\
\hline $\begin{array}{l}\text { Дебиторская задолженность } \\
\text { просроченная на срок от 31 } \\
\text { дней до 90 дней }\end{array}$ & 89348 & $(2048)$ & 87300 & $2,3 \%$ \\
\hline $\begin{array}{l}\text { Дебиторская задолженность, } \\
\text { просроченная на срок свыше }\end{array}$ & 44106 & $(2300)$ & 41806 & $5,2 \%$ \\
\hline $\begin{array}{l}\text { Итого дебиторская задол- } \\
\text { женность по состоянию на } \\
\text { 31 декабря 2018года }\end{array}$ & 902916 & $(16140)$ & 886776 & $1,78 \%$ \\
\hline
\end{tabular}


сумме задолженности;

2) Срок возникновения дебиторской задолженности свыше 45 дней, но меньше 90 дней сумма резерва равна 50\% от суммы задолженности;

3) Срок возникновения дебиторской задолженности менее 45 дней - резерв не создается.

Такой подход, применяемый и в бухгалтерском учете, не ведет к возникновению постоянных налоговых разниц, что, безусловно, упрощает ведение учета по РСБУ. Однако такой подход не приводит к достоверному отражению справедливой стоимости активов в отчетности, т.к. учитывает только прошлый опыт, то есть учитывая уже понесенные, а не ожидаемые убытки.

Во многих случаях компании не применяют требования осмотрительности и большой готовности к признанию расходов, чем доходов, установленные ПБУ 1/2008 «Учетная политика орга- низации», и создают резервы под обесценение дебиторской задолженности только при наличии информации об инициировании процедуры банкротства дебитора или уже случившемся прекращении его деятельности [1]. В таком случае речь о достоверном представлении дебиторской задолженности в финансовой отчетности не идет.

Концепция справедливой стоимости имеет существенное значение для всех групп внутренних и внешних пользователей отчетности. Сближение стандартов российского бухгалтерского учета и системы международных стандартов финансовой отчетности путем внедрения в РФ федеральных стандартов бухгалтерского учета должно способствовать использованию концепции справедливой стоимости в системе бухгалтерского учета и бухгалтерской (финансовой) отчетности.

\section{Библиографический список}

1. ПБУ $1 / 2008$ Учетная политика // Электронный ресурс URL: http://www.consultant.ru/cons/cgi/online.cgi?req= doc \&base $=$ LAW \&n=221028\&fld=134\&dst=100014,0\&rnd=0.6656124389171332\#08955801721662031

2. МСФО (IFRS) 13 «Оценка справедливой стоимости» // Электронный ресурс URL: http://www.consultant.ru/ document/cons_doc_LAW_193740/75e6a38fad9c44420bb065b13c6d6fc368525db3/

3. Международный стандарт финансовой отчетности (IFRS) 9 «Финансовые инструменты» (введен в действие на территории Российской Федерации в редакции 2014 года Приказом Минфина России от 27.06.2016 N 98н) (ред. от 16.09.2019) // Электронный ресурс URL: http://www.consultant.ru/document/cons_doc_LAW_202060/

4. «Международный стандарт финансовой отчетности (IAS) 39 «Финансовые инструменты: признание и оценка» (введен в действие на территории Российской Федерации Приказом Минфина России от 28.12.2015 N 217н) (ред. от 11.07.2016) // Электронный ресурс URL: http://www.consultant.ru/document/cons_ doc_LAW_193673/

5. Федеральные стандарты бухгалтерского учета // Электронный ресурс URL: https://www.minfin.ru/ru/ perfomance/accounting/accounting/legislation/positions/

6. НК РФ Статья 266. Расходы на формирование резервов по сомнительным долгам // Электронный ресурс URL: http://www.consultant.ru/document/cons_doc_LAW_28165/85f4b05570b918c09d4855cc6175021e9065c993/ 